\title{
Two-Phase Flow and Transport in the Air Cathode of Proton Exchange Membrane Fuel Cells
}

\author{
Z. H. Wang and C. Y. Wang \\ GATE Center for Advance Energy Storage \\ Department of Mechanical and Nuclear Engineering \\ Pennsylvania State University \\ University Park, PA 16802 \\ K. S. Chen \\ Engineering Sciences Center \\ Sandia National Laboratories \\ Albuquerque, NM 87185-0834

A manuscript submitted to

Journal of Electrochemical Society

as a technical paper 


\section{DISCLAIMER}

This report was prepared as an account of work sponsored by an agency of the United States Government. Neither the United States Government nor any agency thereof, nor any of their employees, make any warranty, express or implied, or assumes any legal liability or responsibility for the accuracy, completeness, or usefulness of any information, apparatus, product, or process disclosed, or represents that its use would not infringe privately owned rights. Reference herein to any specific commercial product, process, or service by trade name, trademark, manufacturer, or otherwise does not necessarily constitute or imply its endorsement, recommendation, or favoring by the United States Government or any agency thereof. The views and opinions of authors expressed herein do not necessarily state or reflect those of the United States Government or any agency thereof. 


\section{DISCLAIMER}

Portions of this document may be illegible in electronic image products. Images are produced from the best available original document. 


\begin{abstract}
Two-phase flow and transport of reactants and products in the air cathode of proton exchange membrane (PEM) fuel cells is studied analytically and numerically. Four regimes of water distribution and transport are classified by defining three threshold current densities and a maximum current density. They correspond to first appearance of liquid water at the membrane/cathode interface, extension of the gas-liquid two-phase zone to the cathode/channel interface, saturated moist air exiting the gas channel, and complete consumption of oxygen by the electrochemical reaction. When the cell operates above the first threshold current density, liquid water appears and a two-phase zone forms within the porous cathode. A two-phase, multi-component mixture model in conjunction with a finite-volume-based computational fluid dynamics (CFD) technique is applied to simulate the cathode operation in this regime. The model is able to handle the situation where a single-phase region co-exists with a two-phase zone in the air cathode. For the first time, the polarization curve as well as water and oxygen concentration distributions encompassing both single- and two-phase regimes of the air cathode are presented. Capillary action is found to be the dominant mechanism for water transport inside the two-phase zone. The liquid water saturation within the cathode is predicted to reach $6.3 \%$ at $1.4 \mathrm{~A} / \mathrm{cm}^{2}$.
\end{abstract}




\section{Introduction}

Water management is critical to achieving high performance of PEM fuel cells. As a vessel of protons, the polymer electrolyte membrane requires sufficient water to exhibit a high ionic conductivity. During fuel cell operation, water molecules migrate through the membrane under electro-osmotic drag and Fickian diffusion, making it difficult to retain a high water content within the membrane. Generally, humidification is applied to the inlets of the anode and/or cathode in order to supply water to the membrane region. On the other hand, water is generated at the cathode/membrane interface due to the electrochemical reaction of $\mathrm{H}^{+} / \mathrm{O}_{2}$. If the water generated is not removed from the cathode at a sufficient rate, cathode flooding may result and the oxygen gas transport is hindered. Thus a relatively dry air at the cathode inlet is sometimes helpful to remove excessive water.

Modeling water transport and distribution in PEM fuel cells has been attempted in recent years. Bernardi ${ }^{1}$ analyzed the effects of different operating conditions on the water balance in fuel cells. Wang and Savinell ${ }^{2}$ included the electrode structure effects on water transport in the catalyst layer. With a two-dimensional membrane-electrode model, Fuller and Newman ${ }^{3}$ simulated a PEM fuel cell operation under the condition of moist gas in electrodes. They obtained the water distribution in the membrane and the net water flux across it. Nguyen and White ${ }^{4}$ compared three humidification designs using a combined heat and mass transfer model. Springer et al. ${ }^{5}$ predicted the net water-per-proton flux ratio across the membrane. In a later work, Springer et al. ${ }^{6}$ fitted their predicted results to the experimental data by assuming that the presence of liquid water only modifies the

effective porosity for oxygen gas transport. Bemardi and Verbrugge ${ }^{7.8}$ formulated a 
simplified one-dimensional model for liquid water transport in porous electrodes assuming a constant liquid volume fraction and no interactions between liquid and gas flows.

Recently, Gurau et al. ${ }^{9}$ applied a comprehensive model of fluid dynamics and species transport to a full PEM fuel cell. Similarly, Yi and Nguyen ${ }^{10}$ analyzed twodimensional hydrodynamics and multi-component transport in an interdigitated cathode. It should be noted that these recent models are valid only in the absence of liquid water and they do not account for water condensation and evaporation phase change within porous electrodes.

The importance of two-phase transport in PEM fuel cells has been repeatedly stressed in the literature ${ }^{5.6}$. During fuel cell operation, especially at high current densities, liquid water is likely to appear in the cathode, resulting in two-phase transport phenomena. The transport processes then become significantly more complicated due to the coupled flow of liquid water and gaseous reactants in porous media ${ }^{11,12}$. Liquid water transport by capillary action, dynamic interaction between single- and two-phase zones via evaporation and condensation, and effects of the phase distribution on gas transport remain to be explored.

The present paper describes a combined analytical and numerical study of gasliquid, two-phase flow and transport in the air cathode of PEM fuel cells. Next, an orderof-magnitude analysis is attempted to define various transport regimes, which is followed by an accurate numerical model based on the multiphase mixture model previously developed by Wang and Cheng ${ }^{13}$ for two-phase flow and multicomponent transport in porous media. Two-dimensional simulations are presented to corroborate the analytical 
results as well as to study the two-phase hydrodynamics and transport of air and liquid water and its effects on performance of the PEM fuel cell cathode.

\section{Problem Statement and Order-of-Magnitude Analysis}

Consider a porous cathode adjacent to a flow channel, as shown in Fig. 1. The oxygen reduction reaction at the membrane/cathode interface consumes oxygen and generates water. Transport of the reactant and product occurs in the porous cathode and flow channel. As the current density (i.e. the water generation rate) increases, water is present first as vapor only but gradually condenses to liquid thus leading to the development of two-phase flow and transport in the air cathode.

Before attempting a full numerical model of the transport processes encompassing both single- and two-phase situations, we present below a simple classification of various regimes of cathode operation and analytically determine their respective threshold current densities. These regimes are:

- Regime I (when $0<I<I_{(r)}$ ): A single-phase region is present throughout the air cathode and flow channel (see Fig.2);

- Regime II (when $I_{c r l}<I<I_{c r 2}$ ): A two-phase zone starts to appear in the vicinity of the membrane/cathode interface and the remainder of the air cathode is still in the single-phase region. The two-phase zone and single-phase region are separated by an evaporation front whose location is unknown a priori but determined by the coupled flows in both regions; 
- Regime III (when $I_{c r 2}<I<I_{c r 3}$ ): The cathode is largely occupied by the two-phase mixture and liquid water starts to appear along the cathode/channel interface, however the flow channel remains in the gas phase; and

- Regime IV (when $I_{c r 3}<I<I_{\max }$ ): Liquid water appears inside the flow channel and a two-phase mixture exists throughout the cathode and its adjacent channel.

To obtain analytical estimates of the above threshold current densities defining various regimes, consider a one-dimensional water transport process along $y$-direction only: Water generated at the membrane/cathode interface is transported through the cathode into the gas channel and then carried away to the channel exit. Assuming that the net water transport across the membrane to the cathode is quantified by a net water transport coefficient, the rate of water generation at the membrane/cathode interface can then be expressed, according to Faraday's law, as

$$
\left.j^{H: O}\right|_{y=H}=-\frac{M^{H: O}(1+2 \alpha)}{2 F} I
$$

where $\alpha$ is the net water transport coefficient across the membrane, i.e. the ratio of the water flux across the membrane from the anode to the proton flux transported. Physically, this water flux is a combined result of electro-osmotic drag and molecular diffusion.

In the case of no liquid formation, gas diffusion is generally the main mechanism for water transport through the porous cathode and gas convection is negligible due to the small permeability. The water vapor flux across the cathode can thus be calculated by

$$
\left.j_{g}^{H_{2} O}\right|_{y=H_{s c}}=-D_{g}^{H_{2} O} \varepsilon \frac{\left.\rho_{g}^{H_{2} O}\right|_{y=H}-\left.\rho_{g}^{H_{2} O}\right|_{y=H_{3 c}}}{H-H_{g c}}
$$


where $\left.\rho_{g}^{H_{2} \mathrm{O}}\right|_{y=H}$ represents the water vapor density at the membrane/cathode interface. The water vapor density at the cathode/channel interface, $\left.\rho_{g}^{H_{2} O}\right|_{y=H_{z c}}$, depends on the mass exchange process between the porous cathode and gas channel. Using the average water vapor density in the gas channel, $\overline{\rho_{g, f l o w}^{H_{2} O}}$, one can express the mass flux of water vapor at the cathode/channel interface as:

$$
\left.j_{g}^{H_{2} O}\right|_{y=H_{z c}}=-h_{m}\left(\left.\rho_{g}^{H_{2} O}\right|_{y=H_{g c}}-\overline{\rho_{g, f l o w}^{H_{2} O}}\right)
$$

where $h_{m}$ is the mass transfer coefficient between the porous cathode and gas channel. Combining Eqs. (2) and (3) results in:

$$
\left.j_{g}^{H_{2} O}\right|_{y=H_{s c}}=-\frac{\left.\rho_{g}^{H_{2} O}\right|_{y=H}-\overline{\rho_{g . \text { flow }}^{H_{2} O}}}{\frac{1}{h_{m}}+\frac{H-H_{g c}}{D_{g}^{H_{2} O} \varepsilon}}
$$

The two mass transfer resistances in the denominator of Eq.(4) are representative of diffusion in the cathode and convection mass exchange between the cathode and channel, respectively. The water removal flux given by Eq.(4) should then be equal to the water generation rate given by Eq.(1) under the steady-state condition.

When the water vapor density at the membrane/cathode interface reaches the saturated value corresponding to the operating temperature, liquid water begins to appear, marking the end of the first regime. Combining equations (1) and (4) thus yields the following first threshold current density:

$$
I_{c r l}=\frac{\rho_{g, \text { sut }}^{H_{2} O}-\overline{\rho_{g . j l o w}^{H_{2} O}}}{\frac{1}{h_{m}}+\frac{H-H_{g c}}{D_{g}^{H_{2} O} \varepsilon}} \cdot \frac{2 F}{M^{H_{2} O}(1+2 \alpha)}
$$


If the cell current density exceeds $I_{c r l}$, a gas-liquid zone appears in the vicinity of the membrane/cathode interface. An evaporation front separates the two-phase zone from the single-phase region in the remainder of the cathode. Liquid phase transport becomes a transport mechanism for the water generated at the membrane/cathode interface and transported through the two-phase zone to the evaporation front where liquid water evaporates and is removed in the vapor form via gas diffusion and convection. The evaporation front propagates towards the flow channel and the two-phase zone expands as the current density increases. The second threshold current density takes place when the evaporation front reaches the cathode/channel interface. Hence, according to Eqs.(1) and (3), one has

$$
I_{c r 2}=\frac{\rho_{g . \text { sat }}^{H_{2} O}-\overline{\rho_{g . j \mathrm{flww}}^{H_{2} O}}}{\frac{1}{h_{m}}} \cdot \frac{2 F}{M^{H_{2} O}(1+2 \alpha)}
$$

Note that both the first and second threshold current densities given by Eqs.(5) and (6) are dependent on the average water vapor density in the gas channel. This parameter increases down the channel due to the continual addition of water vapor from the cathode; namely,

$$
u_{\text {in }} H_{g c}\left(\widetilde{\rho_{g ; \text { fluw }}^{H_{2} O}}-\rho_{g, \text { in }}^{H_{2} O}\right)=\int_{0}^{x}\left(-\left.j^{H_{2} O}\right|_{y=H}\right) d x \approx \frac{M^{H_{2} O}(1+2 \alpha)}{2 F} I x
$$

With Eq.(7), Eqs.(5) and (6) can now be rewritten as:

$$
\begin{aligned}
& I_{c r 1}=\frac{2 F}{M^{H_{2} O}} \cdot \frac{\rho_{g . s a t}^{H_{2} O}\left(1-R H_{i n}\right)}{1+2 \alpha} \cdot\left(\frac{L}{H_{g c}} \cdot \frac{1}{u_{i n}}+\frac{1}{h_{m}}+\frac{H-H_{g c}}{D_{g}^{H_{2} O} \varepsilon}\right)^{-1} \\
& I_{c r 2}=\frac{2 F}{M^{H_{2} O}} \cdot \frac{\rho_{g . s a t}^{H_{2} O}\left(1-R H_{i n}\right)}{1+2 \alpha} \cdot\left(\frac{L}{H_{g c}} \cdot \frac{1}{u_{i n}}+\frac{1}{h_{m n}}\right)^{-1}
\end{aligned}
$$


where

$$
R H_{\text {in }}=\frac{\rho_{g, \text { in }}^{H_{2}, O}}{\rho_{g, \text { sat }}^{H_{2} O}}
$$

is the relative humidity of gas at the inlet. Note that the first threshold current density is dependent on the water vapor diffusion resistance in the porous cathode, the mass transfer resistance at the porous cathode/gas channel interface, and the ability of dry air in the channel to carry away water vapor. The diffusion resistance in the porous cathode becomes irrelevant for the second threshold current density.

It is evident from Eq.(7) that the average water vapor density at the exit of the flow channel may reach the saturated value corresponding to the cell temperature, marking the end of the third regime. Accordingly, the third threshold current density can be estimated from Eq.(7) as follows:

$$
I_{c r 3}=\frac{2 F}{M^{H_{2} O}} \frac{H_{g c}}{L} \cdot \frac{\rho_{g, s a t}^{H_{i} O}\left(1-R H_{i n}\right)}{1+2 \alpha} u_{i n}
$$

Any current density higher than $I_{c r 3}$ requires water to be removed from the flow channel in the liquid form, leading to a two-phase flow of gas and liquid within the flow channel.

Finally, there exists an absolutely maximum current density at which all oxygen supplied into the flow channel is consumed. Since the oxygen supply rate to the inlet is:

$$
Q_{i n}^{O_{2}}=u_{i n} H_{g c} \rho_{g, i n}^{O_{2}}
$$

according to Faraday's law, the maximum current density is then given by:

$$
I_{\max }=\frac{4 F}{M^{O_{2}}} \frac{Q_{i n}^{O_{2}}}{L}=\frac{4 F}{M^{O_{2}}} \frac{H_{g c}}{L} u_{\text {in }} \rho_{g . i n}^{O}
$$

where $\rho_{g_{\text {in }}}^{O_{2}}$ can be determined from the ideal gas law. 
All parameters required to estimate the four current densities are readily available from the operating conditions except for the net water transport coefficient and the mass transfer coefficient at the interface between the porous cathode and flow channel. The net water transport coefficient is a combined result of electro-osmotic drag and Fickian diffusion in the membrane region, thus its rigorous determination requiring a full cell analysis. Some estimate of this parameter has been made by $\mathrm{Yi}$ and Nguyen ${ }^{10}$.

To estimate the mass transfer coefficient at the cathode/channel interface, consider mass transfer in a fully laminar flow through a parallel-plate channel with a constant mass flux applied at one surface and no-flux at the other. In this situation, the dimensionless mass transfer coefficient defined by Sherwood number is given by ${ }^{15}$ :

$$
S h=\frac{h_{m} H_{g c}}{D_{g}}=2.693
$$

Although the fuel-cell flow channel differs slightly from the geometry described above because the cathode/channel interface is permeable, the calculation based on the detailed numerical results to be reported in the following yields a Sherwood number of 2.637 for the present problem. This good agreement with Eq.(14) not only indicates that there is negligibly small flow through the cathode of low permeability, but also confirms that the interfacial mass transfer coefficient can be safely represented by Eq.(14).

Using the properties listed in Table 1 and the operating parameters summarized in Table 2, Figure 3 illustrates the effect of the air inlet velocity on the four threshold current densities. It can be seen that the maximum and the third threshold current densities linearly increase with the air inlet velocity, as apparent from Eqs.(11) and (13). However, the dependence of both the first and second threshold current densities on the air inlet velocity is weaker, especially under large velocity conditions. In fact, the first 
threshold current density approaches an asymptotic value at $u_{\text {in }}$ of about $2 \mathrm{~m} / \mathrm{s}$, implying that the water vapor transport is limited only by diffusion through the porous cathode under this condition.

While the above approximate analysis and classification yield simple quantification of different regimes of water transport and distribution in the air cathode, accurate modeling of two-phase flow and transport must be performed numerically as to be shown in the next section.

\section{Numerical Modeling}

Several prior models have treated the first regime described above, namely the single-phase operation of the air cathode $9 \cdot 10.16$. The second regime that involves twophase flow and transport in the air cathode has yet to be modeled. Moreover, no model has been able to include both the first and second regimes as well as their transition. Therefore, the main objective of this section is to present a unified model that encompasses both the first and second regimes and ensures a smooth transition between the two. To account for liquid phase transport by capillary action in the two-phase zone, evaporation-condensation phase change at the evaporation front, and multicomponent gas transport due to both diffusion and convection within the single-phase region, the multiphase mixture model previously developed by Wang and co-workers ${ }^{13,}$ 17-21 is conveniently applied. The reader is referred to Wang and Cheng ${ }^{13}$ for details of the multiphase mixture model and its applications to a number of multiphase transport problems in porous media. In the following, only the governing equations for the present problem are summarized. 


\section{Governing Equations}

Continuity

$$
\frac{\partial(\varepsilon \rho)}{\partial t}+\nabla \cdot(\varepsilon \rho \mathbf{u})=0
$$

Momentum Conservation

$$
\frac{\partial(\varepsilon \rho \mathbf{u})}{\partial t}+\nabla \cdot(\varepsilon \rho \mathbf{u} \mathbf{u})=\nabla \cdot(\varepsilon \mu \nabla \mathbf{u})-\varepsilon \nabla p+\varepsilon \rho_{\mathbf{x}} \mathbf{g}-\varepsilon^{2} \frac{\mu}{K} \mathbf{u}
$$

Species Conservation

$$
\begin{aligned}
\frac{\partial}{\partial t}(\varepsilon \rho C)+\nabla \cdot\left(\varepsilon \gamma_{c} \rho \mathbf{u} C\right) & =\nabla \cdot(\varepsilon \rho D \nabla C) \\
& +\nabla \cdot\left\{\varepsilon\left[\rho_{l} s D_{l} \nabla C_{l}+\rho_{g}(1-s) D_{g} \nabla C_{g}-\rho D \nabla C\right]\right\} \\
& -\nabla \cdot\left[\left(C_{l}-C_{g}\right) \mathbf{j}_{l}\right]
\end{aligned}
$$

Here, the momentum balance equation has been modified to be valid in both the porous cathode and the open flow channel, reducing to the extended Darcy's law for two-phase flow in porous media and the Navier-Stokes equation inside the flow channel with the porosity being unity and the permeability being infiniteness. Note that $\mathbf{u}$ is the intrinsic velocity vector based on the open pore area only. The species transport equation is applicable to oxygen $\left(\mathrm{O}_{2}\right)$ as well as water $\left(\mathrm{H}_{2} \mathrm{O}\right)$. Also, the species concentration has been used instead of the partial density employed in the foregoing order-of-magnitude analysis. They are related by:

$$
\begin{gathered}
C_{j}^{i}=\frac{\rho_{j}^{i}}{\rho_{j}} \\
C^{i}=\frac{\rho^{i}}{\rho}
\end{gathered}
$$

where species $i$ represents $\mathrm{O}_{2}$ or $\mathrm{H}_{2} \mathrm{O}$ and subscript $j$ denotes a gas $(g)$ or liquid $(l)$ phase. 
A unique feature of the multiphase mixture model is that it does not need to track phase interfaces separating single- from two-phase regions and hence greatly simplifies numerical simulation of the present problem. In fact, all the above governing equations identically reduce to their single-phase counterparts in the limits of the liquid saturation, $s$, equal to zero and unity, respectively.

\section{Mixture parameters}

In the goveming equations (15)-(17), the mixture variables and properties are defined as:

Density

$$
\rho=\rho_{l} s+\rho_{g}(1-s)
$$

Concentration

$$
\rho C=\rho_{l} C_{l} s+\rho_{g} C_{g}(l-s)
$$

Velocity

$$
\rho \mathbf{u}=\rho_{l} \mathbf{u}_{l}+\rho_{g} \mathbf{u}_{g}
$$

Kinetic density

$$
\rho_{\kappa}=\rho_{l} \lambda_{l}(s)+\rho_{g} \lambda_{g}(s)
$$

Viscosity

$$
\mu=\frac{\rho_{l} s+\rho_{g}(1-s)}{\left(k_{r l} / v_{l}\right)+\left(k_{r g} / v_{g}\right)}
$$

Diffusion coefficient

$$
\rho D=\rho_{l} s D_{l}+\rho_{g}(1-s) D_{g}
$$

Advection correction factor $\gamma_{c}=\frac{\rho\left(\lambda_{l} C_{l}+\lambda_{g} C_{g}\right)}{\rho_{l} s C_{l}+\rho_{g}(1-s) C_{g}}$

Relative mobilities

$$
\lambda_{l}(s)=\frac{k_{r l} / v_{l}}{k_{r l} / v_{l}+k_{r g} / v_{g}} \quad ; \quad \lambda_{g}(s)=1-\lambda_{l}(s)
$$

In addition to the above conservation equations, the multiphase mixture formulation embodies the following important relation for calculating the individual phase velocities from the mixture flow field: 


$$
\mathbf{j}_{t}=\frac{\lambda_{l} \lambda_{g} K}{v}\left[\nabla p_{c}+\left(\rho_{l}-\rho_{g}\right) \mathbf{g}\right]
$$

Physically, the first term on RHS represents the capillary flow due to the gradient in meniscus curvature, whereas the second term accounts for gravity-induced phase migration. The individual phase velocities (i.e. intrinsic velocities based on the open pore area rather than phase-occupied areas) are then calculated from

$$
\begin{aligned}
& \varepsilon \rho_{l} \mathbf{u}_{l}=\mathbf{j}_{l}+\lambda_{l} \varepsilon \rho \mathbf{u} \\
& \varepsilon \rho_{g} \mathbf{u}_{g}=-\mathbf{j}_{l}+\lambda_{g} \varepsilon \rho \mathbf{u}
\end{aligned}
$$

\section{Constitutive Relations}

The relative permeabilities for liquid and gas phases are well represented by ${ }^{17}$ :

$$
k_{r l}=s^{3} \quad \text { and } \quad k_{r g}=(1-s)^{3}
$$

and the capillary pressure between the two phases can be expressed as ${ }^{13}$

$$
p_{c}=\sigma\left(\frac{\varepsilon}{K}\right)^{1 / 2}\left[1.417(1-s)-2.120(1-s)^{2}+1.263(1-s)^{3}\right]
$$

\section{Equilibrium Conditions}

Liquid water appears in the porous cathode only when the water vapor pressure reaches its saturated value at the operating temperature. Inside the two-phase zone, thermodynamic equilibrium is assumed to hold true, and thus the concentrations of water in gas and liquid phases given by their equilibrium values, respectively, are:

$$
C_{g, s a t}^{H, O}=\frac{M^{H_{2} O} p_{v}(T)}{R \rho_{g} T} \quad \text { and } \quad C_{l, s a t}^{H_{2} O}=1
$$


where $p_{v}(T)$ is the water vapor saturation pressure and can be obtained from the steam table. Thus, the liquid saturation, $s$, can be determined from the mixture concentration of water, $C$, via the following relation:

$$
s=\frac{\rho_{g}\left(C^{H_{2} \mathrm{O}}-C_{g, \text { sat }}^{H_{2} \mathrm{O}}\right)}{\rho_{l}\left(C_{l, \text { sat }}^{H_{2} \mathrm{O}}-C^{H_{2} \mathrm{O}}\right)+\rho_{g}\left(C^{H_{2} \mathrm{O}}-C_{g, \text { sat }}^{H_{2} \mathrm{O}}\right)}
$$

Similarly, for oxygen

$$
C_{l, s a t}^{O_{2}}=0 \quad \text { and } \quad C_{g, s a t}^{O}=\left[\frac{\rho_{l} s}{\rho_{g}(1-s)}+1\right] C^{O}
$$

within the two-phase zone, assuming that oxygen is insoluble in the liquid phase.

\section{Boundary Conditions}

At the inlet of the gas channel, constant flow rate and mass concentration of each species are specified. At the outlet, both velocity and concentration fields are assumed to be fully developed. Hence:

At $0<y<H_{g c}:$

$$
\begin{aligned}
& \left.u\right|_{x=0}=u_{i n},\left.v\right|_{x=0}=0,\left.C^{H_{2} O}\right|_{x=0}=C_{i n}^{H_{2} O},\left.C^{O_{2}}\right|_{x=0}=C_{i n}^{O_{2}} \\
& \left.\frac{\partial u}{\partial x}\right|_{x=L}=0,\left.v\right|_{x=L}=0,\left.\frac{\partial C^{H_{2} O}}{\partial x}\right|_{x=L}=0,\left.\frac{\partial C^{O}}{\partial x}\right|_{x=L}=0
\end{aligned}
$$

At $H_{g c} \leq y \leq H$ :

$$
\left.u\right|_{x=0}=0,\left.v\right|_{x=0}=0,\left.\frac{\partial C^{H_{2} O}}{\partial x}\right|_{x=0}=0,\left.\frac{\partial C^{O_{2}}}{\partial x}\right|_{x=0}=0
$$




$$
\left.u\right|_{x=L}=0,\left.v\right|_{x=L}=0,\left.\frac{\partial C^{H_{2} O}}{\partial x}\right|_{x=L}=0,\left.\frac{\partial C^{O_{2}}}{\partial x}\right|_{x=L}=0
$$

At the electrode/membrane interface where the oxygen reduction reaction occurs:

$$
\left.u\right|_{y=H}=0,\left.\varepsilon v\right|_{y=H}=\frac{\left(j^{O_{2}}+\left.j^{H_{2} O}\right|_{y=H}\right.}{\left.\rho\right|_{y=H}}
$$

and

$$
\left.\left[\gamma_{c} \rho \mathcal{E} \nu C-\Gamma \frac{\partial(\rho C)}{\partial y}+\left(C_{l, s a t}-C_{g, s a t}\right) \frac{\lambda_{l} \lambda_{g} K}{v}\left(\rho_{l}-\rho_{g}\right) g\right]\right|_{y=H}=\left.j\right|_{y=H}
$$

for both species $\mathrm{O}_{2}$ and $\mathrm{H}_{2} \mathrm{O}$. Equation (41) was derived by Cheng and Wang ${ }^{21}$ to include three diffusion mechanisms in a compact form: mass diffusion through liquid and gas phases, respectively, and capillary diffusion within the two-phase zone. The effective diffusivity, $\Gamma$, in Eq. (41) is thus defined as:

$$
\Gamma=\varepsilon D_{g} \text { in all gas region; } \Gamma=\frac{\left(C_{l . s a t}-C_{g . s a t}\right) \rho_{l} D_{c}}{\rho_{l} C_{l . s u t}-\rho_{\mathrm{R}} C_{g . s u t}} \text { in the two-phase region }
$$

where the capillary diffusion coefficient, $D_{c}$, is given by:

$$
D_{c}=\frac{\lambda_{l} \lambda_{g} K}{v}\left(-\frac{d p_{c}}{d s}\right)
$$

The $\mathrm{O}_{2}$ mass flux at this boundary can be expressed as:

$$
\left.j^{O_{2}}\right|_{y=H}=\frac{M^{o_{2}}}{4 F} I
$$

whereas the $\mathrm{H}_{2} \mathrm{O}$ mass flux has been given by Eq. (1). Tafel equation is employed to describe the local current density along the electrode/membrane interface; namely,

$$
I=I_{0} \frac{\left.(1-s) C_{g}^{O}\right|_{y=H}}{C_{g . r e f}^{O}} \exp \left(\frac{\alpha_{c} F}{R T} \eta\right)
$$


where the term $(1-s)$ is used to account for the fraction of surface rendered inactive by the presence of liquid water.

At the bottom of the gas channel:

$$
\left.u\right|_{y=0}=0,\left.v\right|_{y=0}=0,\left.\frac{\partial C^{H_{2} O}}{\partial y}\right|_{y=0}=0,\left.\frac{\partial C^{O}:}{\partial y}\right|_{y=0}=0
$$

\section{Cell voltage}

Assuming that the ohmic potential loss in the membrane and the anode overpotential are negligible, the cell potential can then be related to the cathode polarization overpotential by:

$$
V_{c e l l}=V_{o c}-\eta
$$

where $V_{o c}$ is the open circuit potential.

\section{Results and Discussion}

The coupled governing equations (15)-(17) with the boundary equations (36)-(41) and (46) are solved numerically by a finite-volume-based finite difference method. Numerical details were previously given by $\mathrm{Wang}^{17}$ and thus are not repeated here. The relevant parameters used in all simulations reported in the following are listed in Table 1.

Figure 4 shows a simulated polarization curve for a cathode under the operating conditions described in Table 2 . The present curve only considers the voltage loss at the cathode and ignores the anode kinetic polarization and membrane ohmic loss. Thus, the polarization curve is higher than experimental results as expected, but its general trend compares well to typical experiments ${ }^{6}$. At low current densities, the cathode activation 
overpotential is solely responsible for the potential losses of the cell. At-higher current densities, more oxygen is consumed and more water is generated at the cathode/membrane interface due to both the electrochemical reaction and the water transport across the membrane from the anode. The cell polarization then begins to be limited by the transport of $\mathrm{O}_{2}$. As the current density exceeds the first threshold value. i.e. $1.35 \mathrm{~A} / \mathrm{cm}^{2}$ in the present case, more water is produced than that possibly carried away by air from the electrode, and liquid water starts to form in the vicinity of the cathode/membrane interface. The presence of liquid water reduces the pore spaces for oxygen transport to the reaction surface as well as renders part of the surface electrochemically inactive. These effects result in a slightly steeper slope of the polarization curve upon the first threshold current density, as can be seen from Fig.4. Clearly, a two-phase model is warranted for fuel cells operated at such high current densities, an operating range of special interest for transportation applications. An advantage of the present two-phase model is that it not only provides a unified formulation for both single-phase analysis at low current densities and two-phase calculation at higher values, but also predicts and ensures the smooth transition from the single- to two-phase region automatically.

With further increase in the cell current density, the two-phase zone expands and its evaporation front propagates towards the cathode/channel interface. The numerical simulation shows that the evaporation front reaches the cathode/channel interface at an average current density of $1.47 \mathrm{~A} / \mathrm{cm}^{2}$, corresponding to the second threshold current density defined in the analysis presented earlier. In comparison to the numerical values of the first and second threshold current densities (i.e. $1.35 \mathrm{~A} / \mathrm{cm}^{2}$ and $1.47 \mathrm{~A} / \mathrm{cm}^{2}$ as 
indicated in Fig.4), their respective analytical estimates are $1.29 \mathrm{~A} / \mathrm{cm}^{2}$ and $1.88 \mathrm{~A} / \mathrm{cm}^{2}$ as can be obtained from Fig.3. The good agreement in the first threshold current density is surprising, and the reasonable agreement in the second threshold current density is expected, considering that the analytical estimates are only approximate averages over the entire fuel cell flow path.

Figure 5 shows the velocity field of the two-phase mixture in the cathode and gas channel for the Base Case (i.e. at the average cell current density of $1.4 \mathrm{~A} / \mathrm{cm}^{2}$ ). As expected, there is a large difference in the velocity scale between the porous region and the open channel. The mixture velocity in the porous cathode is at least two orders of magnitude smaller than that in the open channel, indicating that gas diffusion is the dominant transport mechanism in the single-phase region of the porous cathode. The flow field in the open channel is fully developed in view of the large aspect ratio of the channel length to width (equal to 29 in the present case), as can be seen from Fig.5 where the channel length is, however, not drawn to scale for better view. The velocity distribution in the conventional flow field such as the one studied in the present work is relatively simple and could be analytically determined: however, a numerical analysis based on the comprehensive model as presented here becomes necessary for complex designs such as the interdigitated flow field ${ }^{10}$. Magnified plots of individual phase velocity fields within the porous cathode region are presented in Figs. 8(a) and 8(b) and discussed in detail therein.

Figure 6 displays the water vapor concentration distribution in the porous cathode and flow channel. As the air flows down the channel, water vapor is continually added from the cathode resulting in an increased water vapor concentration along the channel. 
This leads to a decreased concentration gradient in water vapor and hence a lower water vapor diffusion rate from the cathode/membrane surface to the gas channel. As a result, liquid water may first appear in the vicinity of the cathode/membrane interface near the channel outlet. A two-phase zone at this location is indeed predicted in the present simulation shown in Fig.6, where the water vapor concentration is seen to be kept at the saturated value, i.e. 0.2907 , corresponding to the operating temperature of $80^{\circ} \mathrm{C}$. It is also seen that the two-phase zone is confined within the cathode at the average current density of $1.4 \mathrm{~A} / \mathrm{cm}^{2}$, confirming the foregoing classification of the first and second regimes.

Figure 7 shows the liquid water saturation distribution in the same case. In accordance with Fig.6, liquid water is seen in the upper-right corner to coexist with the saturated water vapor. The largest liquid amount predicted is around $6.3 \%$ at the current density of $1.4 \mathrm{~A} / \mathrm{cm}^{2}$. This value is lower than that reported experimentally, likely because the present study simulates a single channel whereas experimental fuel cell fixtures usually use series-connected channels. With the effective channel length extended, a higher liquid saturation may result. The numerical results indicate that the mass flux of liquid water due to gravity is less than $0.1 \%$ of that caused by capillary action in the two-phase zone. This is because the Bond number ${ }^{22}$, defined as $\frac{\left(\rho_{l}-\rho_{g}\right) g H_{c}^{2}}{\sigma}$, is about 0.04 , implying the negligible gravity effect as compared with the surface tension effect in the two-phase zone. Thus the liquid water is transported mainly by capillary action to the evaporation front. The front can be approximately depicted by the contour of $s=0.01$ shown in Fig.7.

To display individual velocity field of each phase in the porous cathode, the gas and liquid velocities are calculated from the mixture velocity according to Eqs. (29) and 
(30) and shown in Fig. 8 (a) and (b), respectively. Within the two-phase zone, liquid water flows towards the evaporation front under capillary action. The maximum liquid velocity is approximately $2.3 \times 10^{-5} \mathrm{~m} / \mathrm{s}$. The gas velocity field shown in Fig. $8(\mathrm{~b})$ differs from the liquid velocity by three orders of magnitude and displays opposite patterns in the single- and two-phase regions. In the single-phase region, the gas velocity is primarily normal towards the cathode/channel interface due to the non-zero gas velocity created by the electrochemical reaction of $\mathrm{H}^{+} / \mathrm{O}_{2}$. It is noted from Eq. (40) along with Eqs. (1) and (44) that the normal velocity at the reaction surface is negative (pointing away from it), in accordance with the physical process that hydrogen ions are recombined with $\mathrm{O}_{2}$ to produce water. Across the evaporation front, however, the gas flow reverses its direction, leaving away from the evaporation front again due to capillary action in the two-phase zone. The maximum gas velocity is approximately $0.005 \mathrm{~m} / \mathrm{s}$ in the single-phase region while $0.02 \mathrm{~m} / \mathrm{s}$ in the two-phase zone. For a cathode thickness of $0.0005 \mathrm{~m}$ and the gas diffusivity of around $3 \times 10^{-5} \mathrm{~m}^{2} / \mathrm{s}$ for both water vapor and oxygen, the Peclet number for gas transport is thus 0.08 and 0.32 for single- and two-phase zones, respectively. This implies a definitely negligible contribution of gas convection in the single-phase region but some effect of gas convection in the two-phase zone.

Figure 9 shows the oxygen concentration distribution in both the cathode and open channel at the same current density of $1.4 \mathrm{~A} / \mathrm{cm}^{2}$. It can be seen that about $40 \%$ of the inlet oxygen has been consumed at the half length of the channel. At higher current densities, this fraction becomes larger, leaving the channel outlet section nearly depleted of oxygen. A direct consequence of the non-uniform oxygen concentration profile along the reaction surface is the non-uniform current density distribution because the oxygen 
reduction reaction is first-order as indicated by $\mathrm{Eq}$. (45). This is shown in Figure 10 where the local current density is equal to $2.22 \mathrm{~A} / \mathrm{cm}^{2}$ at the inlet but only $0.86 \mathrm{~A} / \mathrm{cm}^{2}$ near the outlet. Thus, the water generated at the inlet is 2.5 times of that at the outlet. With increasing average current density, the non-uniformity of the current density profile becomes more severe. Therefore, a large amount of water is generated near the cathode inlet where a large local current density prevails. At the same location, the removal rate of water via diffusion is high also. The opposite is true for the cathode outlet. Therefore, a liquid island may form anywhere within the cathode as a result of the balance between water generation and removal.

A slightly abrupt change in the slope is also noted from Fig. 10 at $x=0.8 \mathrm{~cm}$ for the local current density profile. This location corresponds exactly to the beginning of the two-phase zone along the reaction surface. The local current density is reduced as liquid water forms and subsequently impedes the oxygen supply to the electrochemical reaction surface. On the other hand, the reduced electrochemical reaction rate could diminish the liquid water zone thus leading to a higher current density. The interaction between the liquid water formation and electrochemical reaction at the cathode/membrane interface, leading to an oscillatory behavior, has been well observed in fuel cell experiments, especially when the cathode is partially flooded.

\section{Conclusions}

Four regimes of water transport and distribution in PEMFC air cathodes have been classified and their respective boundaries defined by three threshold current densities and a maximum current density. They correspond to first appearance of liquid 
water at the membrane/cathode interface, arrival of the gas-liquid two-phase zone at the cathode/channel interface, saturated moist air exiting the flow channel, and complete consumption of oxygen by the electrochemical reaction. Estimates of the three threshold current densities and the maximum current density were analytically obtained. A twophase flow and transport model was developed to predict liquid water formation and its effects on electrochemical kinetics at the cathode/membrane interface and reactant and product transport in the air cathode. The present model is novel in that it encompasses both single- and two-phase regimes corresponding to low and high current densities and therefore is capable of predicting the transition between the two regimes. It was found that the onset of liquid water formation occurs around $1.35 \mathrm{~A} / \mathrm{cm}^{2}$ for a $5 \mathrm{~cm}^{2}$ fuel cell, in good agreement with experimental results ${ }^{6}$. The water liquid and vapor transport is controlled by capillary action and molecular diffusion, respectively, due to negligible small air velocity within the porous electrode.

The present two-phase model is also applicable to the air cathode of a directmethanol fuel cell (D.MFC) where the two-phase region might be more extensive due to large electroosmotic and diffusion fluxes of liquid water from the DMFC anode. Similarly, the DMFC anode where the liquid phase is a methanol aqueous mixture and the gas phase is carbon dioxide can be treated by the present model.

Future work will:

(i) Integrate the two-phase cathode model into a multi-dimensional full-cell model (Um et $\left.a l^{16}\right)$ to examine overall cell performance at high current densities. This integration will permit addressing the coupling between the water content and water activity determined by state of water at the membrane/cathode interface. In 
other words, the liquid water formation within the cathode may in turn impact the water transport within the membrane and hence its ionic conductivity and ohmic potential drop.

(ii) Use the two-phase model to properly assess the beneficial effects of an interdigitated flow field design on cell performance in the high current density regime.

(iii) Perform quantitative comparisons between the numerical predictions and localized experimental measurements.

\section{Acknowledgments}

This work was partially supported by Sandia National Laboratories. Sandia is a multiprogram laboratory operated by Sandia Corporation. a Lockheed Martin Company. for the United States Department of Energy under Contract DE-AC04-94AL85000. The work is also supported by NSF under Grant No. DUE-9979579.

\section{List of Symbols}

C species mass concentration, $\mathrm{kg} / \mathrm{kg}$

$D \quad$ diffusivity, $\mathrm{cm}^{2} / \mathrm{s}$

F Faraday constant, $96,487 \mathrm{C} / \mathrm{mol}$

g gravitational acceleration, $\mathrm{cm} / \mathrm{s}^{2}$

$H \quad$ total height of cathode and channel, $\mathrm{cm}$

$H_{c} \quad$ cathode thickness, $\mathrm{cm}$

$H_{g c} \quad$ gas channel height, $\mathrm{cm}$ 


\begin{tabular}{|c|c|}
\hline$h_{m}$ & mass transfer coefficient between porous cathode and gas channel, $\mathrm{m} / \mathrm{s}$ \\
\hline$I$ & current density, $\mathrm{A} / \mathrm{cm}^{2}$ \\
\hline$I_{0}$ & exchange current density, $\mathrm{A} / \mathrm{cm}^{2}$ \\
\hline$I_{c r l}$ & first critical current density, $\mathrm{A} / \mathrm{cm}^{2}$ \\
\hline$I_{c r 2}$ & second critical current density, $\mathrm{A} / \mathrm{cm}^{2}$ \\
\hline$I_{c r 3}$ & third critical current density, $\mathrm{A} / \mathrm{cm}^{2}$ \\
\hline$I_{\max }$ & maximum current density, $\mathrm{A} / \mathrm{cm}^{2}$ \\
\hline$j$ & mass flux in $y$ direction, $\mathrm{kg} /\left(\mathrm{cm}^{2} \cdot \mathrm{s}\right)$ \\
\hline$j$ & mass flux vector, $\mathrm{kg} /\left(\mathrm{cm}^{2} \cdot \mathrm{s}\right)$ \\
\hline$K$ & permeability of porous cathode, $\mathrm{cm}^{2}$ \\
\hline$k_{r g}$ & relative permeability of gas phase \\
\hline$k_{r l}$ & relative permeability of liquid phase \\
\hline$L$ & cathode length, $\mathrm{cm}$ \\
\hline$M$ & molecular weight, $\mathrm{kg} / \mathrm{mol}$ \\
\hline$p$ & pressure, $\mathrm{Pa}$ \\
\hline$p_{c}$ & capillary pressure, $\mathrm{Pa}$ \\
\hline$Q$ & mass flow rate, $\mathrm{kg} / \mathrm{s}$ \\
\hline$R$ & gas constant, $\mathrm{J} /(\mathrm{mol} \cdot \mathrm{K})$ \\
\hline$R H$ & relative humidity \\
\hline$S h$ & Sherwood number, $\frac{h_{m} H}{D}$ \\
\hline$s$ & liquid water saturation \\
\hline$t$ & time, $s$ \\
\hline$T$ & temperature, ${ }^{\circ} \mathrm{C}$ \\
\hline
\end{tabular}




\begin{tabular}{|c|c|}
\hline $\boldsymbol{u}$ & intrinsic velocity vector, $\mathrm{cm} / \mathrm{s}$ \\
\hline$u$ & velocity in $x$ direction, $\mathrm{cm} / \mathrm{s}$ \\
\hline$v$ & velocity in $y$ direction, $\mathrm{cm} / \mathrm{s}$ \\
\hline$V_{c e l l}$ & cell voltage, $\mathrm{V}$ \\
\hline$V_{o c}$ & open circuit voltage, $\mathrm{V}$ \\
\hline$x$ & coordinate, $\mathrm{cm}$ \\
\hline$y$ & coordinate, $\mathrm{cm}$ \\
\hline \multicolumn{2}{|c|}{ Greek Symbols } \\
\hline$\alpha$ & net water transport coefficient per proton \\
\hline$\alpha$ & carhodic transfer coefficient \\
\hline$\varepsilon$ & porosity of gas diffusion cathode \\
\hline$\eta$ & overpotential, $\mathrm{V}$ \\
\hline$\mu$ & viscosity, $\mathrm{kg} /(\mathrm{cm} \cdot \mathrm{s})$ \\
\hline$v$ & kinetic viscosity, $\mathrm{cm}^{2} / \mathrm{s}$ \\
\hline$\rho$ & density, $\mathrm{kg} / \mathrm{cm}^{3}$ \\
\hline$\rho_{k}$ & kinetic density, $\mathrm{kg} / \mathrm{cm}^{3}$ \\
\hline$\sigma$ & interfacial tension, $\mathrm{N} / \mathrm{cm}$ \\
\hline \multicolumn{2}{|c|}{ Superscripts } \\
\hline $\mathrm{H}_{2} \mathrm{O}$ & water \\
\hline $\mathrm{O}_{2}$ & oxygen \\
\hline- & average value in gas channel \\
\hline \multicolumn{2}{|c|}{ Subscripts } \\
\hline flow & flow channel \\
\hline
\end{tabular}




$\begin{array}{ll}g & \text { gas phase } \\ \text { in } & \text { inlet } \\ l & \text { liquid phase } \\ r e f & \text { reference value } \\ \text { sat } & \text { saturated water vapor }\end{array}$

\section{References}

1. D. M. Bernardi, J. Electrochem. Soc., 137, 3344 (1990).

2. J. T. Wang and R. F. Savinell, Electrochimica Acta, 37, 2737 (1992).

3. T. F. Fuller and J. Newman, J. Electrochem. Soc., 140, 1218 (1993).

4. T. V. Nguyen and R. E. White, J. Electrochem. Soc., 140, 2178 (1993).

5. T. E. Springer, T. A. Zawodzinski, and S. Gottesfeld, J. Electrochem. Soc., 138, 2334 (1991).

6. T. E. Springer, M. S. Wilson, and S. Gottesfeld. J. Electrochem. Soc., 140. 3513 (1993).

7. D. M. Bernardi and M. W. Verbrugge, AIChE J., 37, 1151 (1991).

8. D. M. Bernardi and M. W. Verbnugge, J. Electrochem. Soc., 139, 2477 (1992).

9. V. Gurau, H. Liu, and S. Kakac, AIChE J., 44, 2410 (1998).

10. J. S. Yi and T. V. Nguyen, J. Electrochem. Soc., 146, 38 (1999).

11. A. E. Scheidegger, The Physics of Flow through Porous Media, University of Toronto Press, Toronto (1958).

12. J. Bear, Dynamics of Fluids in Porous Media, Elsevier, New York (1972).

13. C. Y. Wang and P. Cheng, Advances in Heat Transfer, 30. 93 (1997). 
14. E. L. Cussler. Diffusion: Mass Transfer in Fluid Systems, Cambridge University Press, New York (1984).

15. W. M. Kays and M. E. Crawford, Convective Heat and Mass Transfer, McGraw Hill, New York (1993).

16. S. Um, C.Y. Wang and K.S. Chen, Computational fluid dynamics modeling of proton exchange membrane fuel cells, submitted to J. Electrochemical Society (2000).

17. C. Y. Wang. Numerical Heat Transfer B, Fundamentals, 31, 85 (1997).

18. C. Y. Wang and C. Beckermann, 1993, Int. J. Heat Mass Transfer, 36, 2747 (1993).

19. C. Y. Wang and P. Cheng, Int. J. Heat Mass Transfer, 39, 3607 (1996).

20. C. Y. Wang, Transport Phenomena in Porous Media (eds. by D.B. Ingham and I. Pop), 383, Elsevier Science (1998).

21. P. Cheng and C.Y. Wang, Int. J. Heat Mass Transfer, 39, 3619 (1996).

22. F. D. Incropera and D. P. DeWitt, Fundamentals of Heat and Mass Transfer, John Wiley \& Sons, Inc., New York (1985). 
Table 1 Property parameters used in numerical simulations

\begin{tabular}{llll}
\hline Parameter & Symbol & Value & Reference \\
\hline Water vapor diffusivity & $D_{g}^{H, O}$ & $0.355 \mathrm{~cm}^{2 /} / \mathrm{s}$ & Cussler $^{1+}$ \\
Oxygen diffusivity & $D_{g}^{O}$ & $0.284 \mathrm{~cm}^{2} / \mathrm{s}$ & Cussler $^{1+}$ \\
Porosity of air cathode & $\varepsilon$ & 0.3 & Yi and Nguyen \\
Water transport coefficient & $\alpha$ & 0.3 & Assumed \\
Permeability of porous cathode & $K$ & $1 . \times 10^{-7} \mathrm{~cm}^{2}$ & Gurau et al. \\
Constant in Tafel equation & $I_{0} / C_{g, r e f}^{O}$ & $0.3125 \mathrm{~A} / \mathrm{cm}^{2}$ & Yi and Nguyen ${ }^{10}$ \\
Cathodic transfer coefficient & $\alpha_{c}$ & 2 & - \\
Open circuit potential & $V_{a c}$ & $1.1 \mathrm{~V}$ & Yi and Nguyen ${ }^{10}$ \\
\hline
\end{tabular}

Table 2 Base case and its operating conditions

\begin{tabular}{lll}
\hline Parameter & Symbol & Value \\
\hline Total height of cathode and channel & $H$ & $0.12 \mathrm{~cm}$ \\
Channel height & $H_{g c}$ & $0.07 \mathrm{~cm}$ \\
Cathode length & $L$ & $2 \mathrm{~cm}$ \\
Relative humidity at the inlet & $R H_{i n}$ & $3.43 \%$ \\
Oxygen concentration at the inlet & $C_{g . i n}^{0:}$ & 0.21 \\
Air velocity at the inlet & $u_{i n}$ & $30 \mathrm{~cm} / \mathrm{s}$ \\
Operating pressure & $P$ & $1 \mathrm{~atm}$ \\
Operating temperature & $T$ & $80^{\circ} \mathrm{C}$ \\
Overpotential & $\eta$ & $0.3473 \mathrm{~V}$ \\
\hline
\end{tabular}




\section{LIST OF FIGURES}

Figure 1. Schematic of a PEM fuel cell air cathode.

Figure 2. Four regimes of water distribution in the air cathode and adjacent flow channel:

I: Single-phase throughout porous cathode and flow channel $\left(0<I<I_{c r l}\right)$;

II: A two-phase zone co-existing with the single-phase region with an evaporation front between the two $\left(I_{c r}<l<I_{c r 2}\right)$;

III: Part of the cathode/channel interface is within the two-phase zone but the flow channel stays dry $\left(I_{c r 2}<I<I_{c r 3}\right)$; and

IV: partial flooding of the flow channel by liquid droplets $\left(I_{c r 3}<I<I_{\max }\right)$.

Figure 3. Effect of the air inlet velocity on various threshold current densities and the maximum current density.

Figure 4. Polarization curve encompassing both single- and two-phase regimes of the porous cathode.

Figure 5. Two-phase mixture velocity field in the porous cathode and flow channel at the current density of $1.4 \mathrm{~A} / \mathrm{cm}^{2}$.

Figure 6. Water vapor concentration contours in the porous cathode and flow channel at the current density of $1.4 \mathrm{~A} / \mathrm{cm}^{2}$.

Figure 7. Liquid water saturation contours in the porous cathode and flow channel at the current density of $1.4 \mathrm{~A} / \mathrm{cm}^{2}$. The evaporation front separating the two-phase zone from the single-phase region is approximately represented by the contour of $s=0.01$.

Figure 8(a). Liquid and gas velocity fields at the average current density of $1.4 \mathrm{~A} / \mathrm{cm}^{2}$.

(a) liquid; (b) gas

Figure 9. Oxygen concentration contours in the porous cathode and flow channel at the current density of $1.4 \mathrm{~A} / \mathrm{cm}^{2}$.

Figure 10. Local current density distribution at the average of $1.4 \mathrm{~A} / \mathrm{cm}^{2}$. 


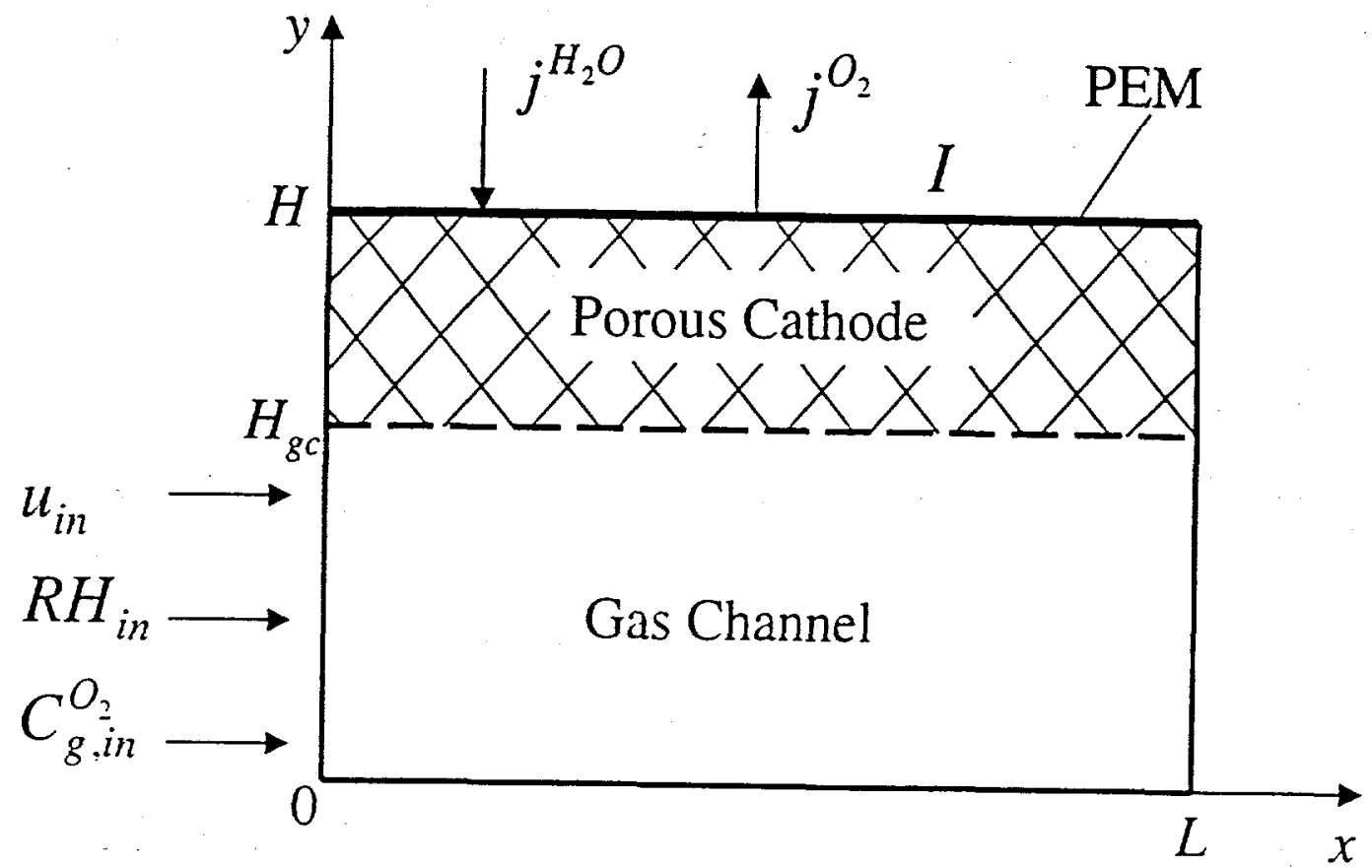

Figure 1. Schematic of a PEM fuel cell air cathode. 


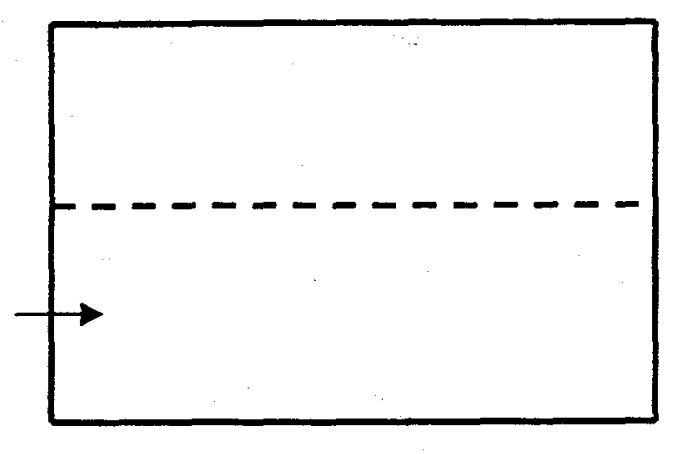

I
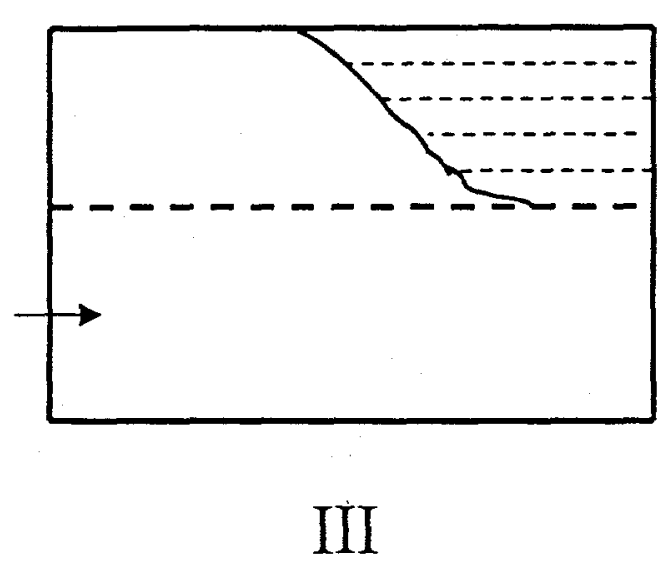

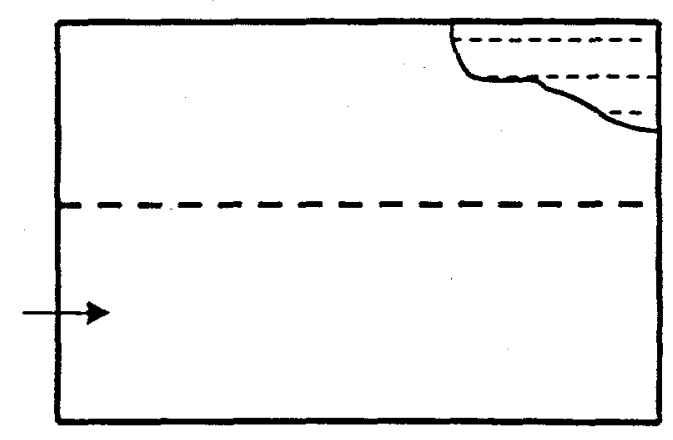

II

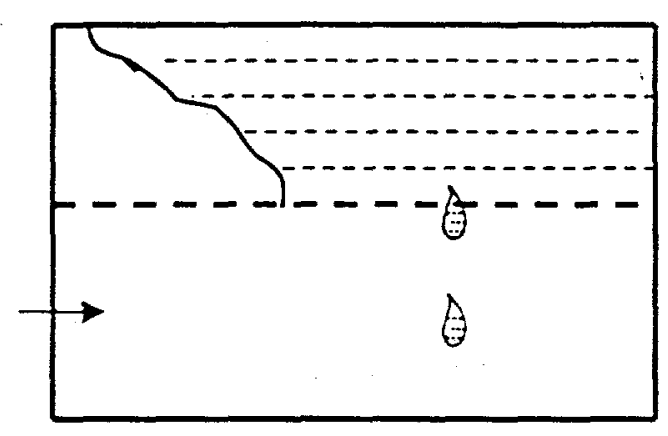

IV

Figure 2. Four regimes of water distribution in the air cathode and adjacent flow channel:

I: Single-phase throughout porous cathode and flow channel $\left(0<I<I_{(r)}\right)$;

II: A two-phase zone co-existing with the single-phase region with an evaporation front between the two $\left(I_{c r 1}<I<I_{c r 2}\right)$;

III: Part of the cathode/channel interface is within the two-phase zone but the flow channel stays dry $\left(I_{c r 2}<I<I_{c r 3}\right)$; and

IV: partial flooding of the flow channel by liquid droplets $\left(I_{c r 3}<I<I_{m u x}\right)$ 


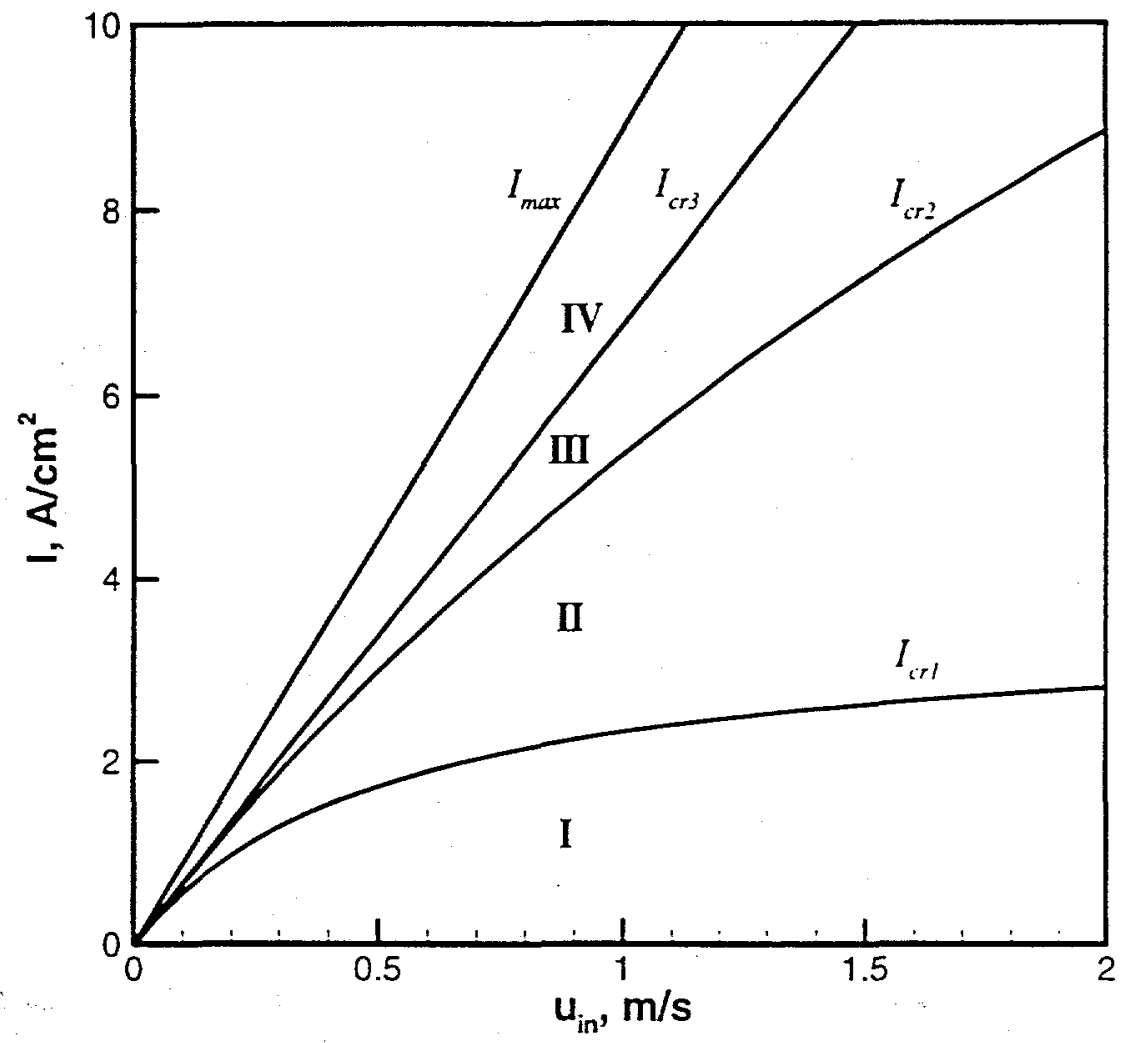

Figure 3. Effect of the air inlet velocity on various threshold current densities and the maximum current density. 


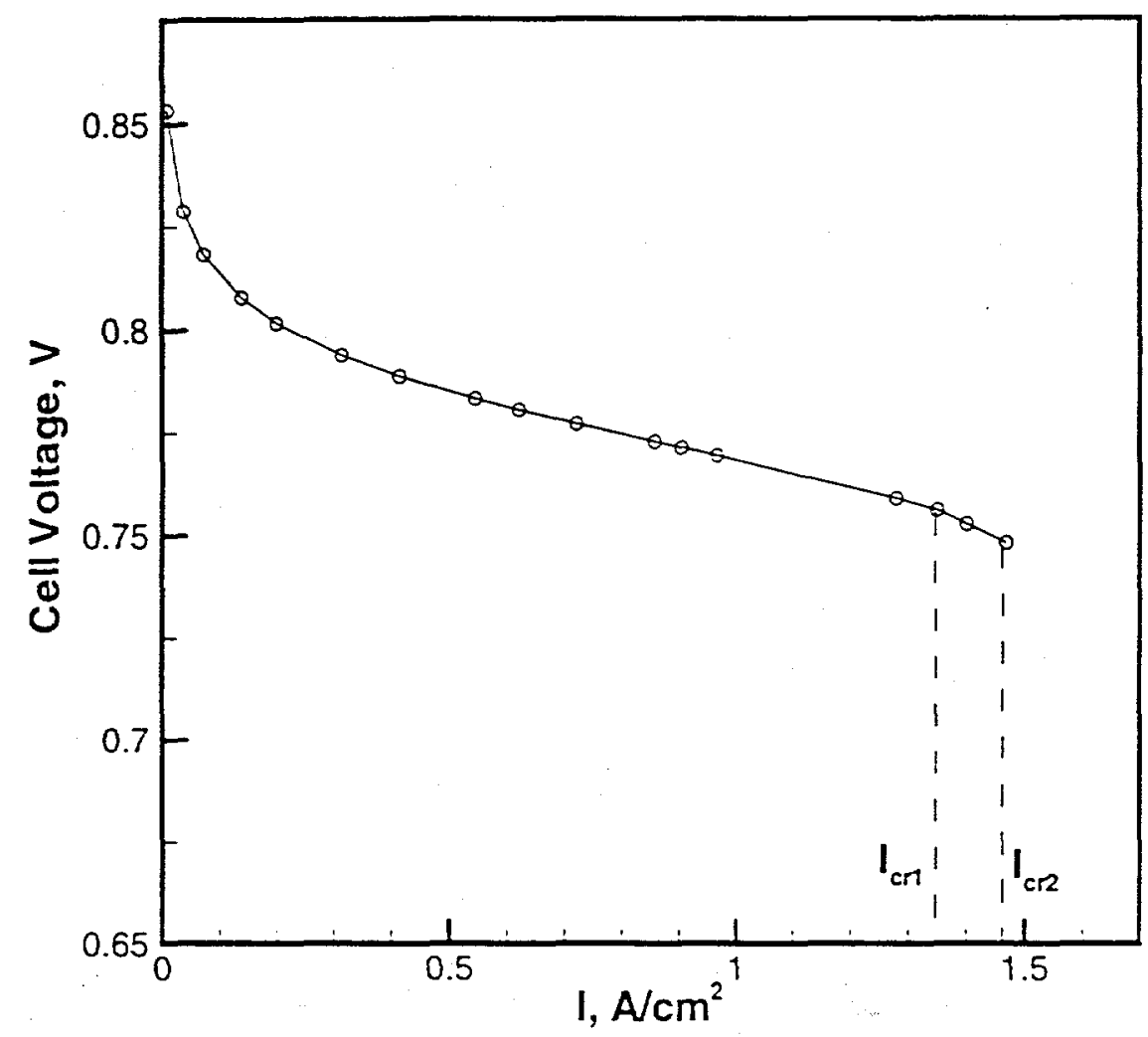

Figure 4. Polarization curve encompassing both single- and two-phase regimes of the porous cathode. 


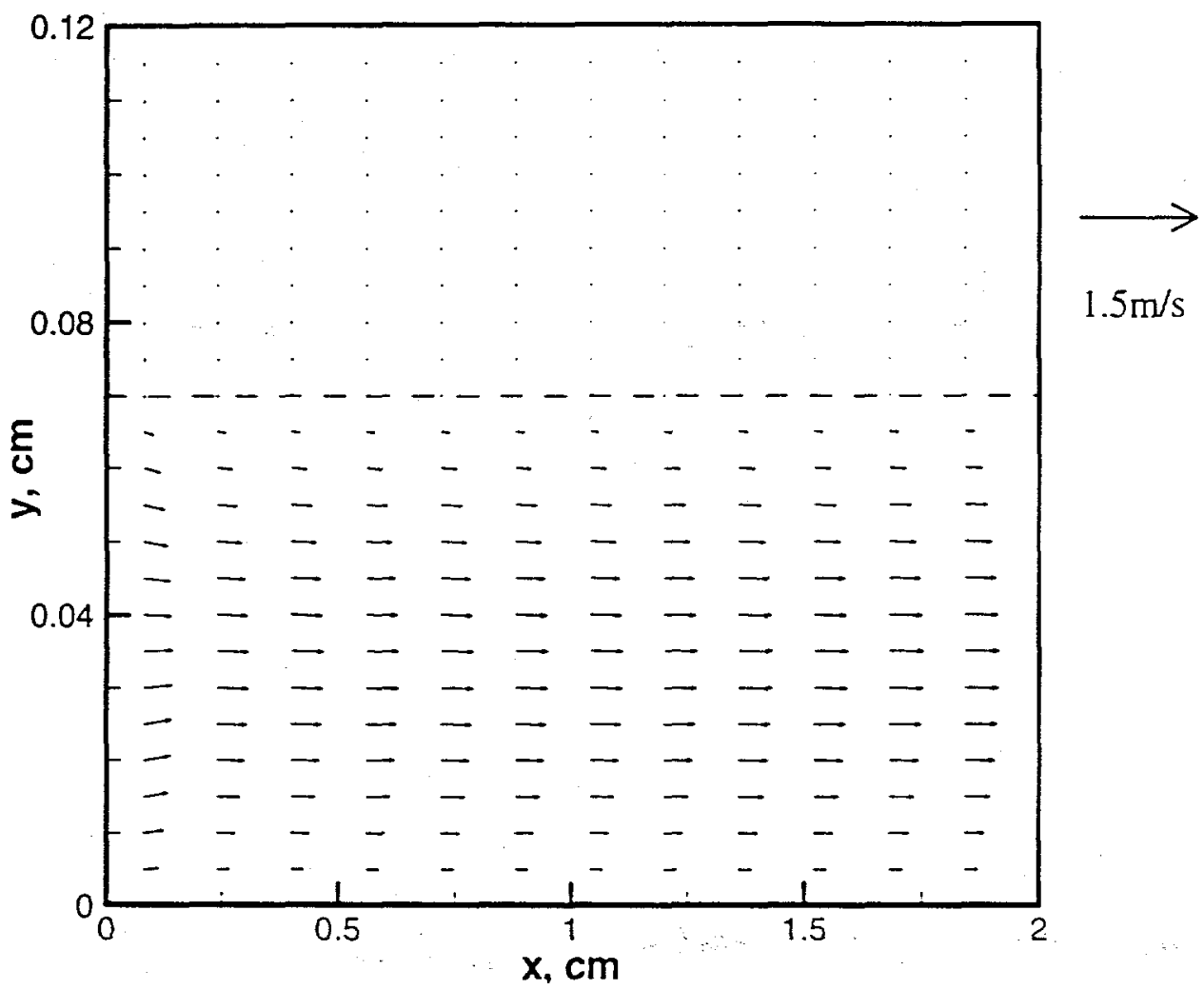

Figure 5. Two-phase mixture velocity field in the porous cathode and flow channel at the current density of $1.4 \mathrm{~A} / \mathrm{cm}^{2}$. 


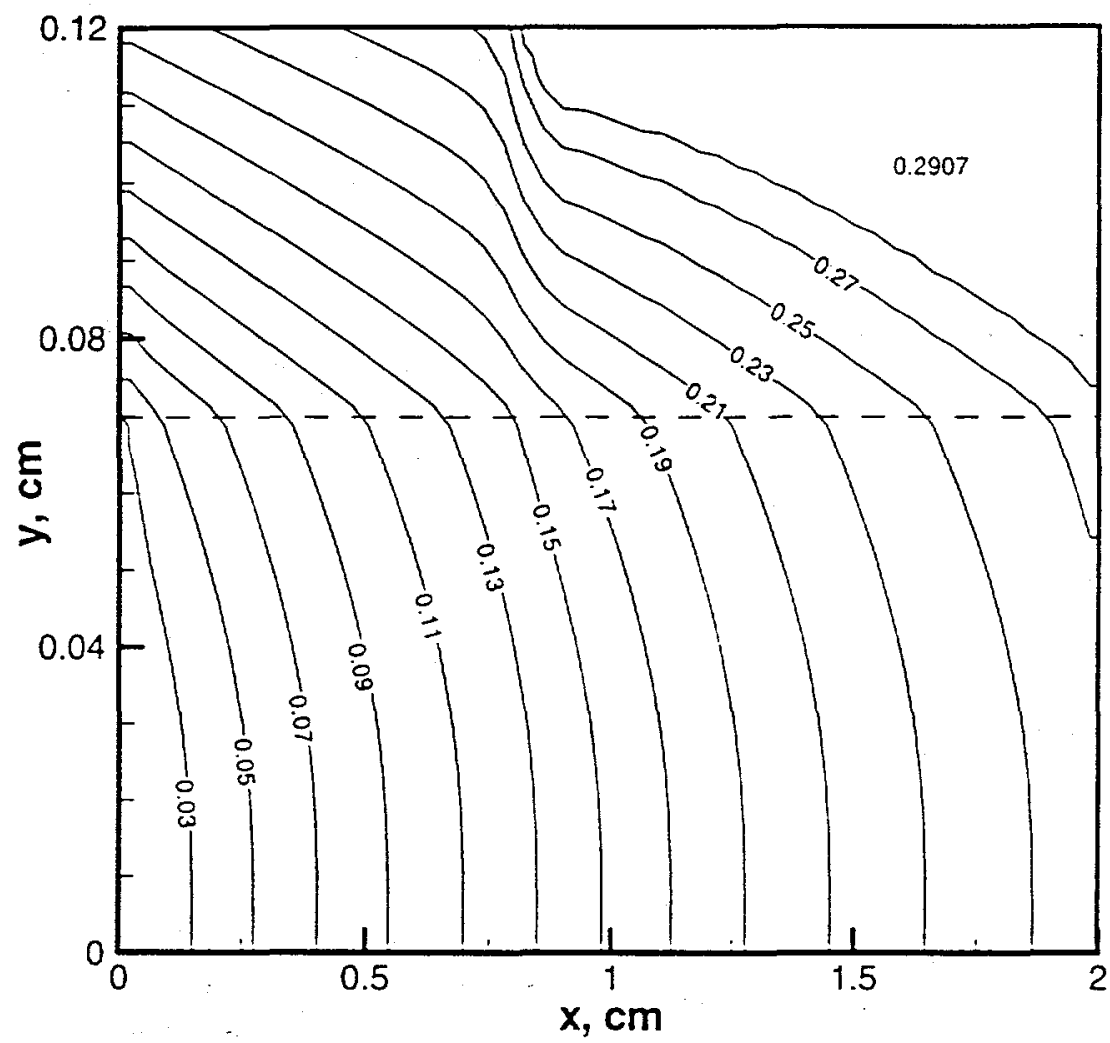

Figure 6. Water vapor concentration contours in the porous cathode and flow channel at the current density of $1.4 \mathrm{~A} / \mathrm{cm}^{2}$. 


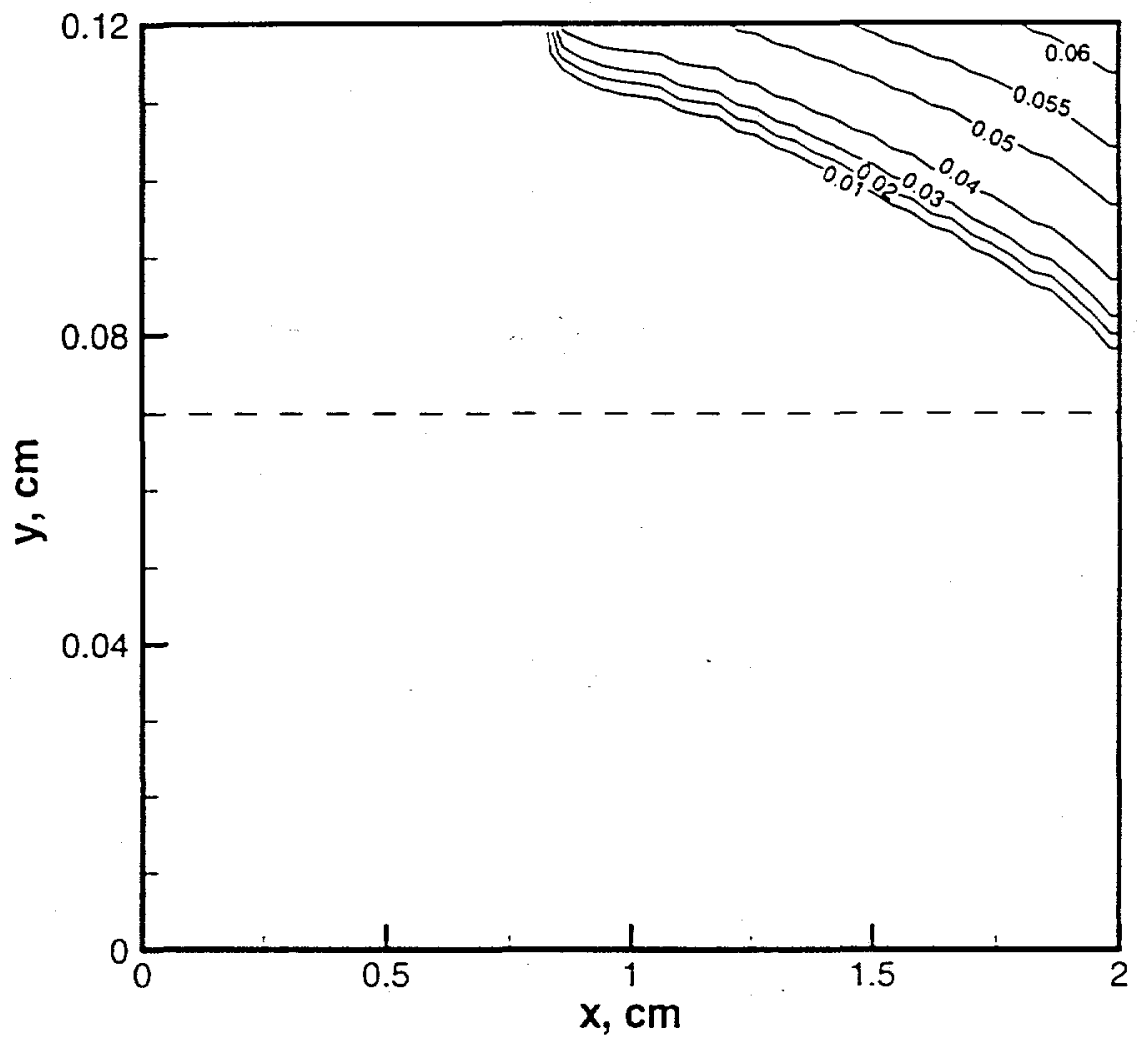

Figure 7. Liquid water saturation contours in the porous cathode and flow channel at the current density of $1.4 \mathrm{~A} / \mathrm{cm}^{2}$. The evaporation front separating the two-phase zone from the single-phase region is approximately represented by the contour of $s=0.01$. 


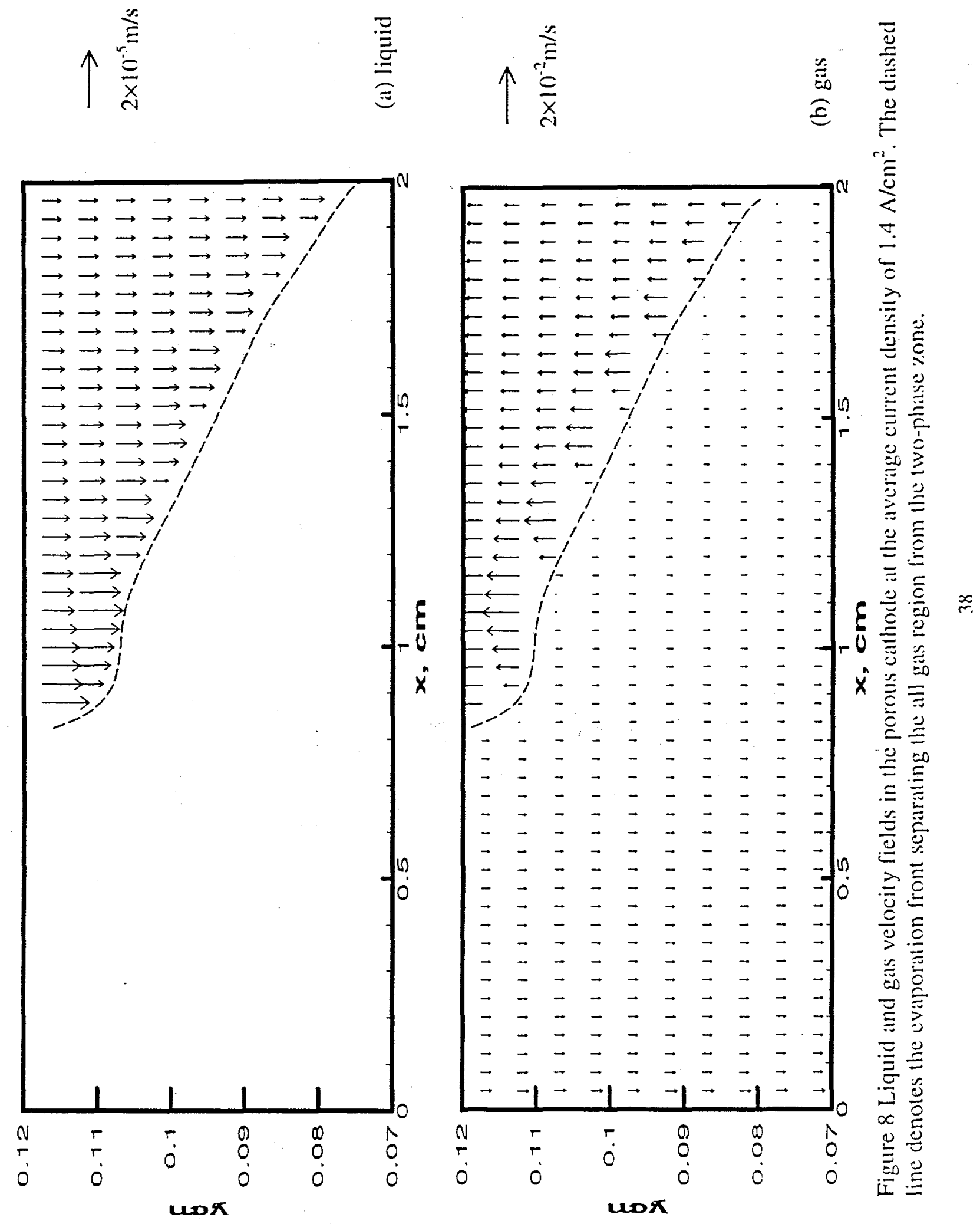




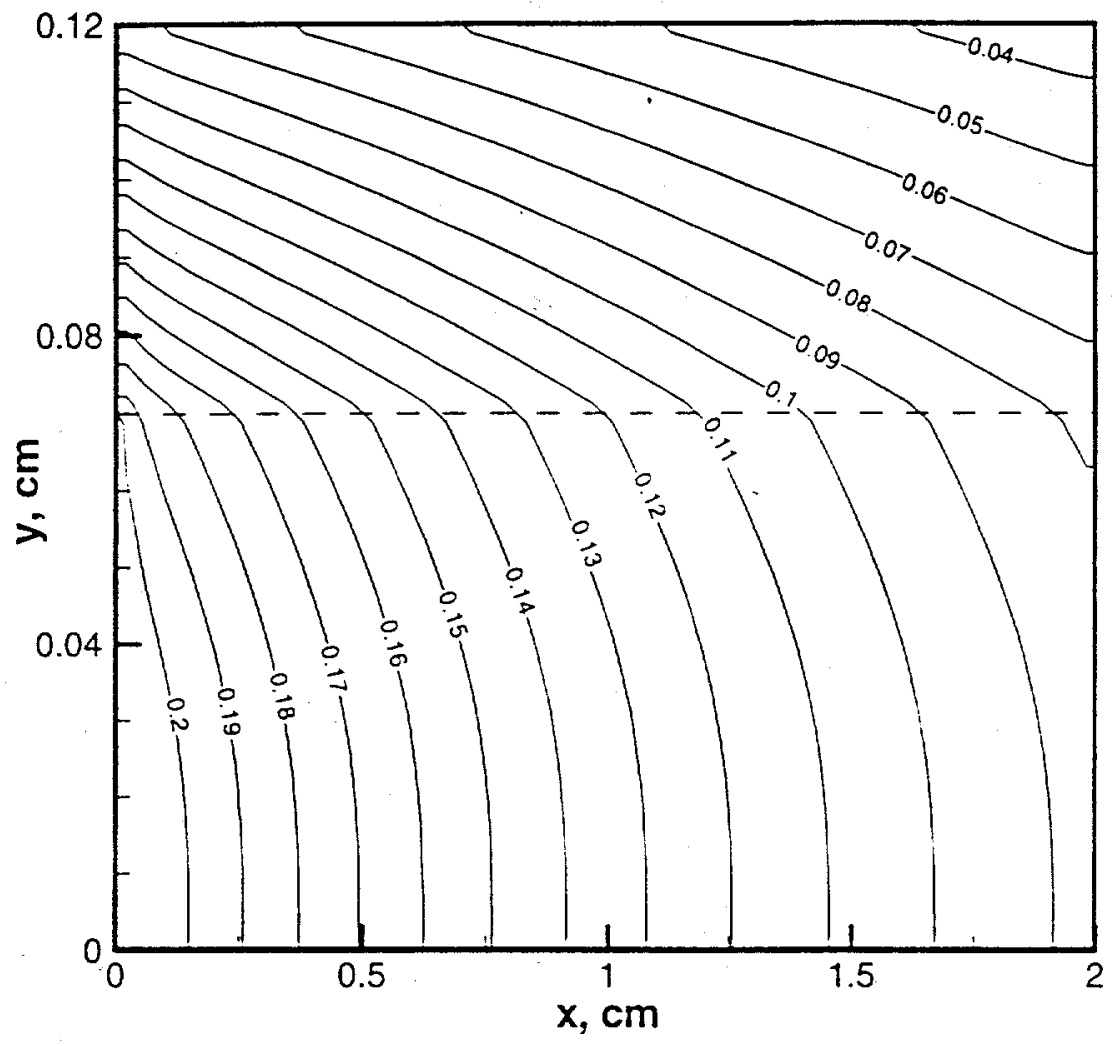

Figure 9. Oxygen concentration contours in the porous cathode and flow channel at the current density of $1.4 \mathrm{~A} / \mathrm{cm}^{2}$. 


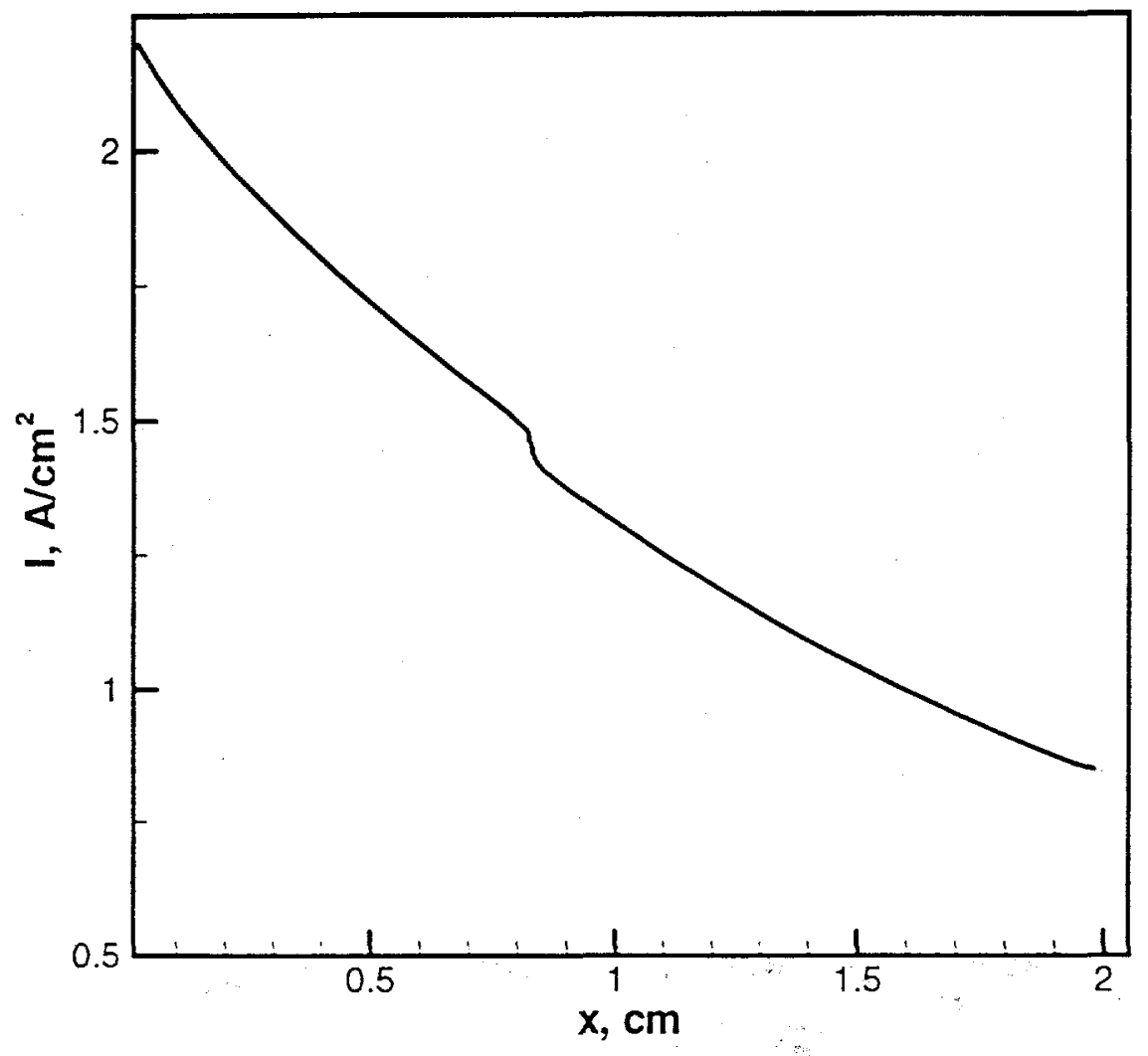

Figure 10. Local current density distribution at the average of $1.4 \mathrm{~A} / \mathrm{cm}^{2}$. 